\title{
Individualism and Collectivism as Moderators of Moral Reasoning and Transformational Leadership Style in the Nigerian Public Sector
}

\author{
Chikelu Okey Felix, Abd Halim B. Ahmad, Rosita Bint Arshad \\ Universiti Utara Malaysia (Northern University of Malaysia), Kedah, Malaysia
}

\begin{abstract}
A plethora of studies reported linkages between ethical reasoning and transformational leadership style, such as moral and ethical leadership, stage of justice reasoning among others. However, few studies investigated the specificities of individual motivational values and belief on the relationship between moral reasoning and transformational leadership style. Nigerians appear to be more collectivistic than individualistic in nature but might be reluctant to compromise personal goals for in-group sentiments due largely to limited resources and opportunities. Few studies on the issue gave conflicting and mixed findings, hence this paper contends that transformational leadership characteristic behaviors facilitate the capacity to know, learn, and anticipate ethical threats that influence the use of post-conventional stage in decision-making. The authors argue that transformational leader's exhibit features that enhance development opportunities in subordinates as they become emotionally glued to their leaders and their duty. Theoretically, individualism connotes personal well-being while collectivism emphasizes more of obligation to the in-group and the degree to which these variables moderate the relationships with leadership styles remain inconclusive. The authors equally suggest that understanding public leaders' degree of moral judgment and behavior may contribute to leadership training and development as leader's core beliefs might affect cognitive processes and behavior in a more hierarchical societies as Nigeria.
\end{abstract}

Keywords: ethical reasoning, transformational leadership, individualism and collectivism

Several studies evidenced the efficacy of transformational leadership on subordinates' ethical behavior and general organizational issues (Burns, 1978; Avolio, Bass, \& Zhu, 2004; Brown \& Trevino, 2006; Grant, 2012). Transformational leaders exert great influence on subordinate's ethical behavior and performance (Avolio, Bass, \& Jung, 1999), provide a conducive environment for innovation (Pearce et al., 2003). Ethics and leadership have been propelled to greater heights as morality is magnified in leadership, while ethics gives an insight into the style of leadership. Attempts are made to promote moral or leadership with ethical dimension

Corresponding author: Chikelu Okey Felix, BA, MPA, CIA, MNIM, Ghazali Shafie Graduate School of Government, Universiti Utara Malaysia (Northern University of Malaysia); research fields: ethics and leadership. E-mail: okey.chikeluf@yahoo.com.

Abd Halim B. Ahmad, professor, Ghazali Shafie Graduate School of Government, Universiti Utara Malaysia (Northern University of Malaysia); research field: social sciences. E-mail: abdhalim@uum.edu.my.

Rosita Bint Arshad, Ph.D. in social sciences, Ghazali Shafie Graduate School of Government, Universiti Utara Malaysia (Northern University of Malaysia); research fields: administration and leadership. E-mail: roz@uum.edu.my. 
in most organizations that desire to remain viable and profitable (Turner, Barling, Epitropaki, Butcher, \& Milner, 2002). The moral degree of leaders in decision-making has been of concern to scholars and practitioners (Bass \& Steidlmeier, 1999; Batmanghlich, 2015; Conger \& Kanungo, 1988; Howell \& Avolio, 1992; Kanungo \& Mendonca, 1998). Other researchers investigated the cultural underpinnings of public leader's ethical behavior.

Despite the glamorous and the positive effects of transformational leaders, its processes, the beliefs, and value systems have necessitated more researches to explore its antecedents (Krishnan, 2001; Bass, 1998; Kirkbride, 2006; Bass \& Avolio, 1997), research evidence that an individual's core beliefs triggers their behaviour and limited studies examined the linkage between leadership and culture (Jung, Bass, \& Sosik, 1995). Literature evidences that organizational culture influences leadership style and behavior, it forms the basis for most problems and solutions as it equally determines how people interact and behave within an organization. Ethics and leadership are mutually reinforcing concepts; leadership is about directing and influencing others' actions for a collective goal (Burns, 1978; Bass \& Avolio, 2000), while ethics are moral compass and reasoning based on norms, tradition, and societal prescriptive beliefs.

Most legitimate governments strive to maintain a virile, efficient, and effective public service to boost socio-political and economic activities through prudent management of scarce resources (Felix, Ahmad, \& Arshad, 2015). In order to achieve the above objective, institutionalizing moral standards and integrity for public officials is proposed. An insight into the core values and beliefs' features of transformational leaders helps to understand the factors underpinning their behavioral and cognitive processes (Krishnan, 2001). It has been argued that the feature of collectivistic culture remains more favourable to transformational leadership behavior than for transactional leadership as ethics is not only about morality, it encompasses duties and obligations as there are upsurge in expectations from the citizenry that the public servant should exhibit higher levels of ethicality coupled with unquestioned integrity, which transformational leadership exhibits.

The study seeks to investigate the linkages between moral reasoning and transformational leadership behavior through the mechanism of individualism and collectivism. Specifically, to address the research question about the degree of moral stage of public sector leaders, as the civil service remains the bedrock of government structure and live-wire of the state. For decades, the Nigeria civil service witnessed a series of reforms as a result of gross inefficiency and ethical lapses, most of the public officers lack the basic administrative knowledge, while some are morally bankrupt.

Despite the overwhelming and growing interest in decision-making related to solving ethical dilemmas, prior studies have not examined specific individual decision-making process related to ethical issues in Nigeria public sector. Consequently, understanding the motivational values, core beliefs, especially the cognitive stage of transformational leaders may enhance their recruitment and development within the sector.

\section{Transformational Leadership}

A considerable attention has been paid to the concept of transformational leadership propounded by Burns (1978), as its positive dimensions are favourable to both followers and organizations. Few studies examined its linkages with specific individual values and beliefs, some conceptual investigations of transformational leadership and broad issues of culture were made (Jung et al., 1995). Dorfman (1996) posited that 
transformational leadership dimensions transcend all cultures as leadership core values should be same globally as attitude, values, norms, and motives to a great extent determines the success or failure of a given task. Public sector organizations, especially school reforms, teacher's motivation are enhanced by transformational leadership (Barnett \& McCormick, 2003), it increases job satisfaction and commitment (Hatter \& Bass, 1988). Yukl and Mahsud (2010) posited that transformational leaders uplift followers' interest, promote creativity, awareness, and nurture relationship with subordinates.

Transformational leaders exhibit no controlling powers, but inspire empowerment and motivation of the subordinates. The four enabling factors associated with transformational leaders are idealized influence which manifests through compassion and empathy (Sarros \& Santora, 2001), the leader exhibits features of a mentor and role model (Krishnan, 2001). Transformational leaders are futuristic through inspirational motivation and being innovative. Through intellectual stimulation, transformational leaders provide a conducive atmosphere for innovation and creativity in solving ethical problems while individual development is enhanced by individualized consideration. Transformational leaders promote followers' perceptions and desires which enhance subordinates' behavior.

However, the emphasis has shifted to examining the factors underlying transformational leadership style and behaviour, to its identification and development. The new trend in research is on the beliefs and core values of transformational leaders, which in both theory and practice enables it to exhibit more influence on subordinate developmental processes (Bass, 1997) by encouraging followers to be creative and innovative when faced with an ethical dilemma. On the other hand, transactional leaders are about what leaders and subordinates gives to each other, a system based on reward and punishment (Bass \& Avolio, 2000). Scholars offer two features of transactional leadership, management by exception (active and passive), contingent reward. Through management by exception, leaders expect full implementation of task from subordinates and only intervene when a deviation is noticed. Transactional leadership is about exchange, expectation and reciprocity which are attributes found in most leadership styles.

\section{Developing Moral Reasoning and Transformational Leadership Style}

Three gray areas of transformational leadership are the underlying core beliefs and values that may influence an individual's style and behavior, the effect of cognition on leaders' behavior and way to identify and develop transformational leadership behaviors (Judge \& Piccolo, 2004; Kanungo, 2001). An insight into Kohlberg's stages of moral development and the application of the DIT (defining issue test), reveals a leaders' level of cognition, as well as various ethical decision-making model by individuals (Trevino, 1986; Jones, 1991), three factors are identified as: (1) the moral domain-perception of a moral problem; (2) judgement-moral reasoning processes; and (3) behavior-outcome. An observed gap exists between reasoning and behavior linkage, which moral intention mediates (Jones, 1991), later, the intensity of moral issue was added as moderator. On the other hand, Trevino (1986) posited that individual and situational factors moderated the relationship between reasoning and behavior, it should be noted that most of all the models never assigned any role in societal culture.

Moral degree of leaders has been of concern to scholars and cognitive processes that influence leader's judgement and behavior was investigated (Berson \& Avolio, 2004; Brown \& Trevino, 2006). It is important to note that each decision made by a leader is usually based on one criterion or the other, therefore ethical reasoning and moral decisions sometimes are based on more than one ethical theory or ethical principle. For 
example, scholars are of the view that different ethical content will naturally invoke a different ethical reasoning approach as in cases of coercion and control; this normally will invoke the act utilitarianism ethical reasoning (Fritzsche \& Becker, 1984). Scholars and practitioners have established a link between ethics and leadership and inferred that leadership needs ethics greatly due to the level of responsibilities of job demands (Avolio, Zhu, Koh, \& Bhatia, 2004), and leadership in government organizations needs more than codes of conduct as they pilot the affairs of the state in all spheres. An ethical dilemma in the public sector is not just about what is right or wrong, rather a choice between two contending rights and how that decision might be made constitute the dilemma.

Kohlberg's cognitive, moral development theory infers that individual's moral reasoning capacity develops over time from pre-conventional, conventional, and post-conventional, the pre-conventional Stage 1 is about individual self where a person obeys laws to avoid punishment; Stage 2, self interest motivates the individual to act morally. The conventional stage is about in-group, family, friends, and peer, Stage 3, morality is about cultivating lasting relationships of benefit in one's in-group, and Stage 4 is about law and order in society as a whole. Post-conventional is about humanity in general and morality is a social contract, the last Stage 6 is based on rationality, self-selected universal principles for achieving social cooperation. Felix et al. (2015) posited that leadership is mirrored through morality. Analysing behavioral reports from subordinates (Avolio, Bass, \& Jung, 1999), inferred that transformational leaders are more post-conventional in reasoning than transactional leaders.

Therefore, individual and contextual elements are involved in ethical judgment (Trevino, 1986), and some of the commonly applied moral principles are the egoism, utilitarianism, deontology, and ethics of care, justice ethics, and rights ethics. The study is based on the conceptual rationalization of some normative ethical principles as the teleology and deontology. Hence, the study of ethical reasoning and transformational leadership style moderated by individualism and collectivism is necessary, especially at this moment of lapses, coupled with fast paced improvement in technology awareness and increasing demand for prudent dispensation of dividends of democracy across the globe.

\section{Public Administration and Cognitive Moral Development}

Public administration is seen as a channel for delivering services to the public (Felix et al., 2015) and it is equally used as a tool of a value expression (Avolio \& Gardner, 2005). Scholars argue that public administration is an institution and an instrument through which credible governments provide the needed socioeconomic and human development of the citizenry. Government on its own is a method of discharging responsibilities of the public officials or civil servants (Goodling, 2003). The idea of a viable public sector in this study means as earlier conceptualized the capacity to honour obligations and discharge responsibilities or functions transparently in an ethical manner through the application of ethical decision-making in work situations.

On the other hand, the public's expectations are twofold, one that the government through its officials will manage and utilize public resources for general well-being of the citizenry and secondly, that the official's behavior should be above board. Bass (1998) indicated that citizens are right to expect efficient and effective social services from the government in areas of health-care, education system, and general security of life and property as this goes a long way to foster public trust. Research has evidenced that public trust and confidence increases when elected and appointed leaders make ethical decisions and exhibit ethical behaviors that promote 
the interest and well-being of the public at large.

Public leaders are prominent in the formulation and implementation of public policies and programs of the government (Adams \& Balfour, 2005), as a result of the tremendous influence they exert, public leader's decisions and actions carry a lot of weight and impact (Felix et al., 2015). Ethics is the heart beat of democratic government in achieving and delivering the dividends of democracy to the people. It was argued argued that ethical conditions for civil servants have been with us for long and actually came with democracy. The importance of ethics in public administration cannot be overemphasized, e.g., Chinua (1983) inferred that ethics are very fundamental elements in a democracy, even the secular and the religious attests to the essence of ethical leadership for effective and efficient administration.

A group of scholars pioneered work and conceptualized the theory that leaders operating at the highest level of CMD (cognitive moral development) relate to transformational leadership style (Turner, Barling, Epitropaki, Butcher, \& Milner, 2002). They made use of DIT and MLQ (multi-leadership questionnaire) on a sample population of 407 participants in the UK and Canada in private sector organizations and an academic institution. At the end of the exercise, it was discovered that leaders with a more complex reasoning ability would be able to draw on more sophisticated conceptualizations of interpersonal situations, and are more likely to think about problems in different ways, and are cognizant of a large number of behavioral options. The Stewart-Sprinthall Management Survey (SSMS) equally assessed the CMD of public leaders in different countries; their major focus was more of demographic study and reported no significant gender difference in US, but higher levels of post-conventional reasoning in females than males in Poland and Russia. Other scholars investigated gender differences of Coast Guard Personnel using DIT (Rest, Narvaez, Thoma, \& Bebeau, 1999), in a sample of 480 and reported significant differences between males and females.

The implication of the above disparities in findings, further buttresses the influence of culture in an organization as the ethical culture at the GSA (government supply agency) is questionable, since research evidenced that CMD influences moral decision when faced with ethical dilemmas (Dibie, 2007; Dunn, 2006). Other scholars examined the theory of power and ethically as an influencing factor in the organization both in public and private (Jurkiewicz, 2005), the study shows significant statistical relations among a high power motive, moral judgement, and executive effectiveness as 202 public administrators were examined in a single organization. The Machiavellian Scale (Mach V) measurement tool for examining power motives was used (Paulhus \& Williams, 2002), while the DIT (Rest et al., 1999) was used for measuring moral reasoning and personnel records, for an example, performance appraisal, subordinates retention history.

The proposition is that if public officials are made up men and women of proven integrity, of sound ethical behavior and character, the incidence of ethical decline and lapses in the public sector will be drastically reduced or eradicated. On the other hand, empirical studies on ethics in government is encouraging, but little is done on ethical reasoning and moral development of public officials and equally very little progress have been made on research concerning moral development and leadership either in public or private organizations (Brown \& Trevino, 2006). Therefore, as leadership behavior is developed as a result of cognitive, moral growth, the need and the capacity of public service leader's influence on the subordinate's ethicality need to be examined. 


\section{Individualism and Collectivism as Potential Moderator}

The rationale behind individualism-collectivism was developed by Triandis (1993), it is argued that values are goals which its attainment must serve the interest of the individual pursuing it and likely to conflict with those that serve collective values. It is argued that the difference between one leadership paradigm and another stems mainly from their values, belief, and ideology (Burns, 1978; Krishnan, 2001; Sarros \& Santora, 2001). Literature evidenced that the transformational leadership holds values and beliefs that distinguish it from other types of leadership styles, as it possess values that enhance individual and professional development in the form of personal achievement, self-direction, and intellectual stimulation (Sarros \& Santora, 2001).

Bass (1997) argued that transformational leadership blended in all cultures and the universality of transformational leadership was based on effectiveness of leaders that practiced transformational leadership style (Dorfman, 1996), unlike those that practice transactional leadership or laissez-fare irrespective of cultures, countries, and organizations. Bass (1997) posited that this universality is only as a concept because specific behaviors linked to each leadership factor might vary from country to another. Muenjohn and Armstrong (2007) examined the extent of cultural influence on leadership behavior using the MLQ and the Value Survey Module (VSM) identified the four cultural dimensions in line with Hofstede (1993), and reported that cultural dimensions had no significant impact on the transformational, transactional, and non-leadership behaviors, but only a small impact of power distance on transformational leadership and this seems to support the universality of the transformational-transactional paradigm proposed by Bass (1997).

Individualism-collectivism is being introduced as a moderating variable to intervene on the relationship between ethical reasoning and transformational leadership style. Other studies have examined the relationship between moral decision and transformational leadership and the influence of culture on transformational leadership (Muenjohn \& Armstrong, 2007), here culture was used as predictor variable on transformational leadership, and no study has considered individualism-collectivism as a mechanism for enhancing or moderating the effect of ethical decision on transformational leadership behavior.

To justify the potentiality of individualism-collectivism as a moderator, the proposition by Schwartz and Bilsky (1990), of the likelihood of conflict or compatibility between value type pairs is significant. Therefore, following Schwartz observations on the 11 identified motivational value types, this study will examine one fundamental question to address the values linked with individualism-collectivism to explore whether all the motivational value types are linked to moral decision-making and if such linkages reinforce or challenge leader's behavior? As attributes of individualism-collectivism constructs, show that individualist cultures emphasize personal goals and personal objectives which are paramount, while the collectivist cultures considers in-group, family, nation, and behave differently toward in-group and out-group. Hence, the following proposition is made:

Proposition 1: Individualism and collectivism will moderate the relationship between moral reasoning and transformational leadership behavior.

\section{Conceptual Framework}

Against the backdrop of the discussion and literature review, this paper proposes a conceptual framework as illustrated in Figure 1 as below. 


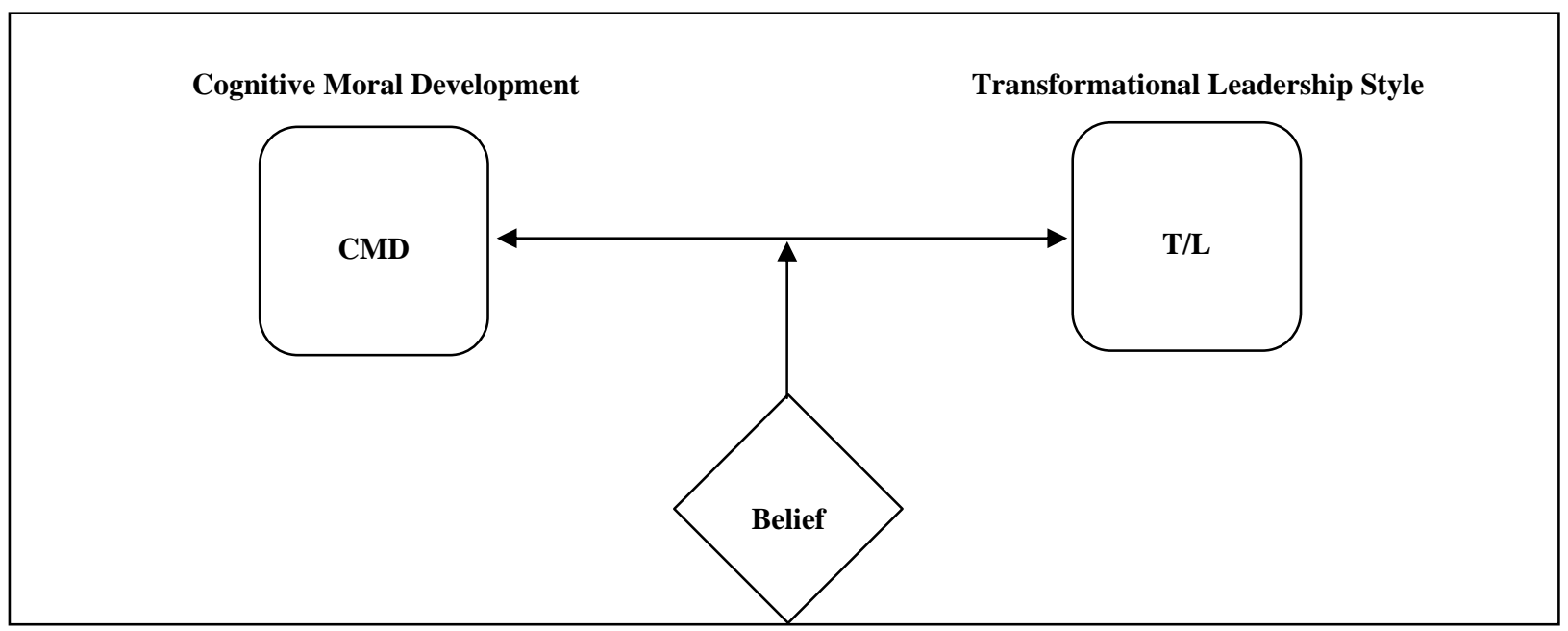

Figure 1. Conceptual framework.

\section{Conclusions}

This study provides some conceptual justification for applying ethical reasoning, beliefs, and core values in the study of transformational leadership in a Nigeria public sector through the mechanism of individualism and collectivism values and belief system as a moderating variable. It made use of considerable works on leadership, ethics, and a body of literature on cultural values and belief. In this instance, this study is an ongoing theoretical research yet to be formally subjected to critical empirical scrutiny. The development of a conceptualized framework is a necessity to buttress or strengthen an already established relationship between moral development and transformational leadership behaviors as perceived by subordinates. It is likely that the specificities of individual values and beliefs will continue to puzzle the minds of leadership researchers and offer new terrains for examinations of their motivational values with regards to moral judgment and behavior, thereby targeting higher cognitive moral development underpinning transformational leadership style.

\section{References}

Adams, G. B., \& Balfour, D. L. (2005). Public-service ethics and administrative evil: Prospects and problems. In H. G. Frederickson and R. K. Ghere (Eds.), Ethics in public management (pp. 114-134). New York: M.E. Sharpe, Inc.

Avolio, B. J., \& Gardner, W. L. (2005). Authentic leadership development: Getting to the root of positive forms of leadership. The Leadership Quarterly, 16(3), 315-338.

Avolio, B. J., Bass, B. M., \& Jung, D. I. (1999). Re-examining the components of transformational and transactional leadership using the Multifactor Leadership. Journal of occupational and organizational psychology, 72(4), 441-462.

Avolio, B. J., Bass, B. M., \& Zhu, F. W. W. (2004). Multifactor leadership questionnaire: Manual and sampler set. Menlo Park, CA: Mind Garden.

Avolio, B. J., Zhu, W., Koh, W., \& Bhatia, P. (2004). Transformational leadership and organizational commitment: Mediating role of psychological empowerment and moderating role of structural distance. Journal of Organizational Behavior, 25(8), 951-968.

Bandura, A. (1993). Perceived self-efficacy in cognitive development and functioning. Educational psychologist, 28(2), 117-148.

Barnett, K., \& McCormick, J. (2003). Vision, relationships and teacher motivation: A case study. Journal of Educational Administration, 41(1), 55-73.

Barnett, T., Bass, K., \& Brown, G. (1994). Ethical ideology and ethical judgment regarding ethical issues in business. Journal of Business Ethics, 13(6), 469-480.

Bar-Yam, M., Kohlberg, L., \& Naame, A. (1980). Moral reasoning of students in different cultural, social, and educational settings. American Journal of Education, 88(3), 345-362. 
Bass, B. M. (1997). Does the transactional-transformational leadership paradigm transcend organizational and national boundaries? American Psychologist, 52(2), 130.

Bass, B. M. (1998). Transformational leadership: Industry, military, and educational impact. Hillsdale, NJ: Erlbaum.

Bass, B. M., \& Avolio, B. J. (2000). Multifactor Leadership Questionnaire: MLQ; sampler set; technical report, leader form, rater form, and scoring key for MLQ Form 5x-short. Palo Alto, CA: Mind Garden.

Bass, B. M., \& Steidlmeier, P. (1999). Ethics, character, and authentic transformational leadership behavior. The Leadership Quarterly, 10(2), 181-217.

Bass, B. M., \&Avolio, B. J. (1997). Full range leadership development: Manual for the Multifactor Leadership Questionnaire (pp. 43-44). Palo Alto, CA: Mind Garden.

Batmanghlich, C. A. (2015). What is Leadership? Why leaders fail ethically (pp. 5-32). Springer International Publishing.

Berson, Y., \& Avolio, B. J. (2004). Transformational leadership and the dissemination of organizational goals: A case study of a telecommunication firm. The Leadership Quarterly, 15(5), 625-646.

Brown, M. E., \& Treviño, L. K. (2006). Ethical leadership: A review and future directions. The Leadership Quarterly, 17(6), 595-616.

Burns, J. B. (1978). Leadership. New York: Harper \& Row.

Chinua, A. (1983). The trouble with Nigeria. Enugu: Fourth Dimension Publishers.

Collier, P., \& Vicente, P. C. (2014). Votes and violence: Evidence from a field experiment in Nigeria. The Economic Journal, 124(574), F327-F355.

Conger, J. A., \& Kanungo, R. N. (1988). The empowerment process: Integrating theory and practice. Academy of Management Review, 13(3), 471-482.

Cooper, T. L. (2004). Big questions in administrative ethics: A need for focused, collaborative effort. Public Administration Review, 64(4), 395-407.

Derry, R., \& Green, R. M. (1989). Ethical theory in business ethics: A critical assessment. Journal of Business Ethics, 8(7), 521-533.

Dibie, R. (2007). Ethical leadership, social responsibility and corruption in Nigeria. Journal of International Politics and Development, 5(1), 1-42.

Dorfman, P. W. (1996). International and cross-cultural leadership research. Handbook for international management research (pp. 267-349).

Dugan, J. P., \& Komives, S. R. (2007). Developing leadership capacity in college students. College Park, MD: National Clearinghouse for Leadership Programs.

Dunn, P. M. (2006). Aristotle (384-322 BC): Philosopher and scientist of ancient Greece. Archives of Disease in Childhood-Fetal and Neonatal Edition, 91(1), F75-F77.

Eckhardt, G. (2002). Culture's consequences: Comparing values, behaviors, institutions and organisations across nations. Australian Journal of Management, 27(1), 89-94.

Felix, C. O., Ahmad, A. H. B., \& Arshad, R. B. (2015). Examining ethical reasoning and transactional leadership style in the nigerian public sector. Journal of Humanities and Social Science, 20(6), 88-94.

Ferrell, O. C., \& Fraedrich, J. (1991). Business ethics: Ethical decision making and cases. Houghton Mifflin College Division.

Fletcher, D., \& Arnold, R. (2011). A qualitative study of performance leadership and management in elite sport. Journal of Applied Sport Psychology, 23(2), 223-242.

Fraedrich, J., \& Ferrell, O. C. (1992). Cognitive consistency of marketing managers in ethical situations. Journal of the Academy of Marketing Science, 20(3), 245-252.

Fraedrich, J., Thorne, D. M., \& Ferrell, O. C. (1994). Assessing the application of cognitive moral development theory to business ethics. Journal of Business Ethics, 13(10), 829-838.

Fritzsche, D. J., \& Becker, H. (1984). Linking management behavior to ethical philosophy—An empirical investigation. Academy of Management Journal, 27(1), 166-175.

Goodling, N. A. (2003). Nigeria’s crisis of corruption-Can the UN Global Programme hope to resolve the dilemma. Vand. J. Transnat'l L., 36, 997.

Grant, M. (2012). The passing of the great race. The Palingenesis Project. Wermod and Wermod Publishing Group.

Hatter, J. B., \& Bass, B. M. (1988). Superiors' evaluation and subordinates' perceptions of transformational and transactional leadership. Journal of Applied Psychology, 73(4), 695.

Hoffman, K. D., \& Siguaw, J. A. (1994). Incorporating ethics into the services marketing class: The case of Sears Auto Centers. 
Marketing Education Review, 4, 26-32.

Hofstede, G. (1993). Cultural constraints in management theories. The Academy of Management Executive, 7(1), 81-94.

Hollander, E. P. (1992). Leadership, followership, self, and others. The Leadership Quarterly, 3(1), 43-54.

Hope, S., \& Ronald, K. (2005). Toward good governance and sustainable development: The African peer review mechanism. Governance, 18(2), 283-311.

Howell, J. M., \& Avolio, B. J. (1992). The ethics of charismatic leadership: Submission or liberation? The Executive, 6(2), 43-54.

Jones, T. M. (1991). Ethical decision making by individuals in organizations: An issue-contingent model. Academy of Management Review, 16(2), 366-395.

Judge, T. A., \& Piccolo, R. F. (2004). Transformational and transactional leadership: A meta-analytic test of their relative validity. Journal of Applied Psychology, 89(5), 755.

Jung, D. I., Bass, B. M., \& Sosik, J. J. (1995). Bridging leadership and culture: A theoretical consideration of transformational leadership and collectivistic cultures. Journal of Leadership \& Organizational Studies, 2(4), 3-18.

Jurkiewicz, C. L. (2005). Power and ethics: The communal language of effective leadership. Ethics in public management (pp. 95-113). New York: M.E. Sharpe, Inc.

Kanungo, R. N. (2001). Ethical values of transactional and transformational leaders. Canadian Journal of Administrative Sciences/Revue Canadienne des Sciences de l'Administration, 18(4), 257-265.

Kanungo, R. N., \& Mendonca, M. (1998). Ethical leadership in three dimensions. Journal of Human Values, 4(2), 133-148.

Kirkbride, P. (2006). Developing transformational leaders: The full range leadership model in action. Industrial and Commercial Training, 38(1), 23-32.

Krejcie, R. V., \& Morgan, D. W. (1970). Determining sample size for research activities. Educational and Psychological Measurement, 30, 601-610.

Krishnan, V. R. (2001). Value systems of transformational leaders. Leadership \& Organization Development Journal, 22(3), 126-132.

Kuhnert, K. W., \& Lewis, P. (1987). Transactional and transformational leadership: A constructive/developmental analysis. Academy of Management Review, 12(4), 648-657.

Muenjohn, N., \& Armstrong, A. (2007). Transformational leadership: The influence of culture on the leadership behaviours of expatriate managers. International Journal of Business and Information, 2(2), 265-283.

Ofori, G. (2009). Ethical leadership: Examining the relationships with full range leadership model, employee outcomes, and organizational culture. Journal of Business Ethics, 90(4), 533-547.

Paulhus, D. L., \& Williams, K. M. (2002). The dark triad of personality: Narcissism, Machiavellianism, and psychopathy. Journal of Research in Personality, 36(6), 556-563.

Pearce, C. L., \& Sims Jr, H. P. (2002). Vertical versus shared leadership as predictors of the effectiveness of change management teams: An examination of aversive, directive, transactional, transformational, and empowering leader behaviors. Group Dynamics: Theory, Research, and Practice, 6(2), 172.

Pearce, C. L., Sims Jr, H. P., Cox, J. F., Ball, G., Schnell, E., Smith, K. A., \& Trevino, L. (2003). Transactors, transformers and beyond: A multi-method development of a theoretical typology of leadership. Journal of Management Development, 22(4), 273-307.

Reiman, J. H. (1990). Justice and modern moral philosophy (p. 69). New Haven, CT: Yale University Press.

Rest, J. R., Narvaez, D., Thoma, S. J., \& Bebeau, M. J. (1999). DIT2: Devising and testing a revised instrument of moral judgment. Journal of Educational Psychology, 91(4), 644.

Sarros, J. C., \& Santora, J. C. (2001). The transformational-transactional leadership model in practice. Leadership \& Organization Development Journal, 22(8), 383-394.

Schein, E. H. (1993). How can organizations learn faster? The challenge of entering the green room. Sloan Management Review, 34(2), 85-92.

Schwartz, S. H., \& Bilsky, W. (1990). Toward a theory of the universal content and structure of values: Extensions and cross-cultural replications. Journal of Personality and Social Psychology, 58(5), 878.

Schwartz, S. H., Verkasalo, M., Antonovsky, A., \& Sagiv, L. (1997). Value priorities and social desirability: Much substance, some style. British Journal of Social Psychology, 36(1), 3-18.

Sorkaa, A. P. (2003). Development as ethics and accountability in governance: The way forward for Nigeria (No. 1). Benue State University.

Trevino, L. K. (1986). Ethical decision making in organizations: A person-situation interactionist model. Academy of 
Management Review, 11(3), 601-617.

Triandis, H. C. (1993). Collectivism and individualism as cultural syndromes. Cross-Cultural Research, 27(3-4), 155-180.

Turner, N., Barling, J., Epitropaki, O., Butcher, V., \& Milner, C. (2002). Transformational leadership and moral reasoning. Journal of Applied Psychology, 87(2), 304.

Yukl, G. (1999). An evaluation of conceptual weaknesses in transformational and charismatic leadership theories. The Leadership Quarterly, 10(2), 285-305.

Yukl, G., \& Mahsud, R. (2010). Why flexible and adaptive leadership is essential. Consulting Psychology Journal: Practice and Research, 62(2), 81. 